\title{
Crohn hastalığının üst gastrointestinal sistem tutulumu: Tek merkez deneyimi
}

\author{
Upper gastrointestinal system involvement of Crohn's disease: Single center experience
}

Muhammet Yener AKPINAR, Yasemin ÖZDERIN ÖZIN, Zeki Mesut Yalın KILIÇ, İsmail Hakkı KALKAN, Mahmut YÜKSEL, Mustafa KAPLAN, Ilyas TENLIK, Özlem AKDOĞAN, Ömer ÖZTÜRK, Ertuğrul KAYAÇETIN

Türkiye Yüksek Ihtisas Eğitim ve Araştırma Hastanesi, Gastroenteroloji Kliniği, Ankara

Giriş ve Amaç: Crohn hastalığı için üst gastrointestinal sistem tutulumu sıklığ \% 0,5-4 arasında değişir. Bu hastaların tedavi ve takipleri ileokolonik hastalıktan farklılık gösterir. Biz bu çalışmada kliniğimizde Crohn hastalığının üst gastrointestinal sistemi etkilediği hastalarımızı sunduk. Gereç ve Yöntem: Hastanemiz Gastroenteroloji Kliniğinde takip edilen ve üst gastrointestinal sistem tutulumu olan Crohn hastaları çalışmaya alındı. Bulgular: 10 hastada üst gastrointestinal sistem tutulumu izlendi. Hastaların yaş ortancasi 40,5 (31-53) olup 6 hasta (\%60) erkek 4 hasta (\%40) ise kadind1. Ortanca takip süresi 29 (1-228) ay olup hastalarnn 4 tanesinde (\%40) izole üst gastrointestinal sistem tutulumu varken geri kalan 6 hastanın (\%60) beraberinde ileal veya ileokolonik hastalığı vardı. Organ tutulumlarına bakıldığında 1 hastada (\%10) özofagus, 2 hastada mide (\%20) ve 7 hastada (\%70) duodenum tutulumu izlendi. Endoskopik görünümler hastadan hastaya değişmekle beraber Crohn hastalığı için tipik sayılan kaldırım taşı görünümü 2 hastada, ülserler 7 hastada ve nodülarite ise 4 hastada endoskopik olarak tanımlandı. Biyopsilerde granülom 3 hastada izlendi (\%30) Sonuç: Crohn hastalığı tanısı olan bir bireyde gelişen epigastrik ağrı, bulantı-kusma ve disfaji gibi şikayetler üst gastrointestinal sistemin endoskopik incelenmesini zorunlu hale getirmektedir. Erken tanı ve uygun tedavi gelişebilecek komplikasyonların önüne geçebilir

Anahtar kelimeler: Crohn hastalı̆̆ı, üst gastrointestinal sistem tutulumu
Background and Aims: The frequency of upper gastrointestinal system involvement in Crohn's disease is $0.5 \%-4 \%$. Treatment and follow-up strategies of these patients differ from those of ileocolonic disease. Here we present our patients who had Crohn's disease with upper gastrointestinal system involvement. Materials and Methods: We retrospectively investigated our patients who had Crohn's disease with upper gastrointestinal system involvement. Results: Upper gastrointestinal system involvement was detected in 10 patients. The median age of patients was 40.5 years (31-53 years); 6 patients were male and 4 patients were female. The median follow-up period after diagnosis was 29 (1-228) months. Four patients had isolated upper gastrointestinal system involvement, while 6 patients had ileocolonic disease. The frequency of organ involvement was $10 \%$ ( 1 patient) for the esophagus, $20 \%$ (2 patients) for the stomach, and $70 \%$ ( 7 patient) for the duodenum. Endoscopic appearances varies among patients; cobble stone appearances were detected in 2 patients, ulcers were detected in 7 patients and nodulariy were detected in 4 patients. Granulomas were detected histopathologically in 3 patients (30\%). Conclusion: Complaints like epigastric pain, nausea and vomiting, and/or dysphagia must warrant clinicians to investigate the upper gastrointestinal system in Crohn's disease. Early diagnosis and appropriate treatment are necessary to prevent complications.

Key words: Crohn's disease, upper gastrointestinal involvement

\section{GIIRISS}

Crohn hastalığı (CH) ilk tanımlandığında terminal ileumun etkilendiği bir hastalık olarak kabul edilmiştir (1). Yıllar içinde CH'nın sadece terminal ileumu etkilemediği, ağızdan anüse kadar gastrointestinal sistemin (GIS) herhangi bir kısminı etkileyebildiği görülmüştür. Montreal sinıflaması içinde $\mathrm{CH}$, GIS tutulum yerine göre Ll'den L4'e kadar dört alt gruba ayrılmış olup üst GIS tutulumu olan hastalar L4 alt sınıfında incelenir (2). Literatürde CH'nda üst GIS tutulumu için bildirilen oran \%0,5-4 arasında değişir $(3,4)$. CH'da üst GIS'in tutulması hastaların tedavi ve takiplerini ileokolonik hastalıktan daha farklı hale getirebilmektedir. Biz bu çalışmada kliniğimizde CH'nın üst GIS’i etkilediği hastalarımızı sunduk.

\section{GEREÇ ve YÖNTEM}

Türkiye Yüksek Ihtisas Eğitim ve Araştırma Hastanesi Gastroenteroloji Kliniği Inflamatuvar Barsak Hastalıkları poliklini-

ğinde takip edilen 3.128 hastanın takip dosyaları retrospektif olarak tarandi. Klinik, radyolojik, endoskopik ve histopatolojik olarak CH tanısı konulan 954 hastanın verileri incelendi. Üst GIS tutulumu olan hastaların bilgileri; ulaşılabildiyse hastaların kendilerinden, hasta dosyaları ve hastane otomasyon sisteminden elde edildi.

\section{BULGULAR}

Çalışmamıza toplam 10 hasta alındı. Hastaların yaş ortancasl 40,5 (31-53) olup 6 hasta (\%60) erkek 4 hasta (\%40) ise kadındı. Ortanca takip süresi 29 (1-228) ay olup hastaların 4 tanesinde (\%40) izole üst Gís tutulumu varken geri kalan 6 hastanin (\%60) beraberinde ileal veya ileokolonik hastallğ vardı. Organ tutulumlarına bakıldığında 1 hastada (\%10) özofagus, 2 hastada mide (\%20) ve 7 hastada (\%70) duodenum tutulumu izlendi (S.ekil 1). Fenotipik olarak 8 hastada

Akpınar MY, Özderin Özin Y, Kilı̧ ZMY, et al. Upper gastrointestinal system involvement of Crohn's disease: Single center experience. Endoscopy Gastrointestinal 2017;25:32-34.

İletişim: Muhammet Yener AKPINAR Türkiye Yüksek İhtisas Eğitim ve Araştırma Hastanesi Gastroenteroloji Kliniği, Kızılay Caddesi Sıhhiye, Ankara Tel: +90 3123061320 • E-mail: muhammet.yener@gmail.com Geliş Tarihi: 13.04.2017 Kabul Tarihi: 17.05.2017 
inflamatuvar, 2 hastada ise striktüran $\mathrm{CH}$ vardı (Tablo 1). Bu hastalarda endoskopi mide ağrısı, bulantı ve/veya kusma gibi spesifik olmayan şikayetlerden dolayı yapılmıştı. Endoskopik görünümler hastadan hastaya değişmekle beraber $\mathrm{CH}$ için tipik sayılan kaldırım taşı görünümü 2 hastada, ülserler 7 hastada ve nodülarite ise 4 hastada endoskopik olarak tanımlandı. Biyopsilerde granülom 3 hastada izlendi (\%30) (Tablo 2). Bu hastaların 2 tanesine ileokolonik hastalıktan dolayı operasyon yapilırken hastanemizdeki takip süreleri boyunca hiçbir hastaya üst gastroduodenal cerrahi yapılmamıştı. Hastaların aldıkları medikal tedaviler de farklılık göstermekteydi; bununla beraber steroid bu hastalarda en çok uygulanılan tedaviydi.

\section{Üst Gastrointestinal Sistemde Crohn Hastalığı Lokalizasyonu}

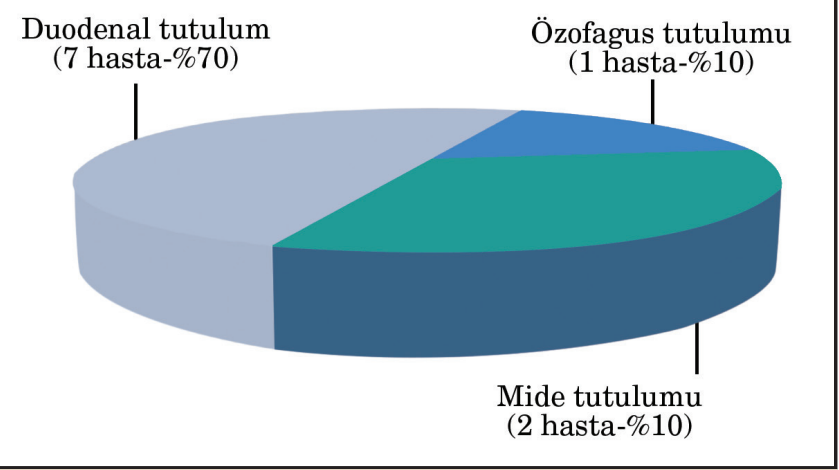

Şekil 1. Crohn Hastalı̆ı̆ın üst gastrointestinal sistem tutulum lokalizasyonları

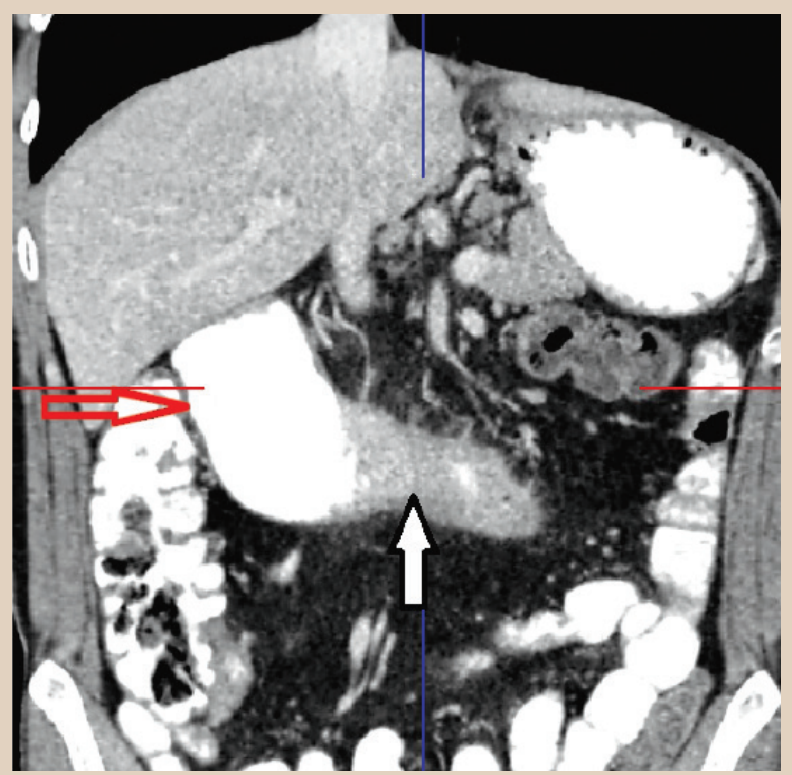

Resim 1. Duodenal Crohn hastasında gelişen stenoz (beyaz ok) ve proksimalindeki dilatasyonun (kırmızı ok) koronal kesitteki görünümü.
Tablo 1. Hastaların demografik verileri ve klinik özellikleri

Hastaların Demografik ve Klinik Özellikleri Say

Hasta sayıs1

Yaş

$40,5(31-53)$

Cinsiyet (Erkek/Kadın)

$6 / 4$

Ortalama takip süresi (ay)

$29(1-228)$

Sigara kullanımı

a- Aktif içici

b- Bırakmış

c- Hiç içmemiş

3

3

Apendektomi hikayesi

$$
\text { a- Var }
$$

Ailede Crohn hastalığı hikayesi

0

Üst gastrointestinal sistem tutulum yeri

$$
\text { a- Özofagus }
$$

b- Mide
1. Fundus-Korpus
2. Korpus -Antrum
c- Duodenum
1. Bulbus
2. Duodenum 2. kisim
3. Duodenum 2.-3. kısım
1

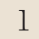

a- lleit

b- Ileokolit

Crohn hastalığı fenotipi

$\begin{array}{ll}\text { a- Inflamatuvar } & 9 \\ \text { b- Striktüran } & 3\end{array}$

Operasyon

Tablo 2. Hastaların endoskopik, histopatolojik özellikleri ve aldıkları tedaviler

Hastaların endoskopik, histolojik özellikleri ve aldıkları tedaviler

Endoskopik görünüm
a- Ülserler
b- Nodülarite
c- Kaldırım taşı manzarası

Histopatolojik olarak granülom varlığı

Medikal tedavi

$$
\text { a- 5-aminosalisilat }
$$

b- 5-aminosalisilat ve steroid

c- 5-aminosalisilat+steroid+azatiopürin

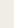

d- 5-aminosalisilat+steroid+azatiopürin+anti-TNF 3 


\section{TARTISSMA}

Çalışmamızda literatürle uyumlu olarak CH'da üst GIS tutulum sıklığı \% 1,04 olarak tespit edildi. Yine literatürle uyumlu olarak duodenum, üst GIS'te en sik etkilenen bölgeydi. Crohn hastalığı için iyi tanımlanmış endoskopik bulgular lineer ülserler ve kaldırım taşı manzarasıdır. Longitudinal ülserler CH'nda yaygın olsa da bu ülserler aynı zamanda iskemik kolit ve Behçet hastalığı gibi hastalıklarda da izlenebilir. Kaldırım taşı manzarası CH için tipik kabul edilse de sıklığı azdır $(5,6)$. Bizim serimizde de hastaların önemli bir kısmında ülserler ve/veya kaldırım taşı manzarası vardı. Bu endoskopik görünümlerin hiçbiri CH'nın GIS'i tuttuğu yerler arasında farklılık göstermez. Bununla beraber Mikihiro ve arkadaşlarının yaptıkları çalışmada bambu kamışı manzarasının (ödemli longitudinal pililerin transvers erozyonlar ve/veya oluklarla kesilmesi sonucu oluşan görünüm) mideyi tutan $\mathrm{CH}$ için tipik bir endoskopik görünüm olduğu tespit edilmiştir (7). İleokolonik CH'nda izlenen patolojik bulgular üst GIS'i tutan CH'da da izlenir. Bununla beraber granülomlar ileokolonik $\mathrm{CH}^{\prime}$ dan daha sik izlenir (8).

Gastroduodenal tutulumlu CH'nın çoğu klinikte asemptomatiktir. Epigastrik ağrı en sık izlenen bulgulardandır. Bunu dispepsi, erken doygunluk, bulantı ve kusma, kilo kaybı gibi şikayetler izler. Bizim serimizde de hastaların başlıca şikayetleri epigastrik ağnıdı. Duodenal tutuluma bağlı gelişen stenozlarda kusma ve kilo kaybi daha belirgin hale gelir $(9,10)$. Gastrointestinal sistem kanaması bu hastalarda kendini daha çok demir eksikliği anemisi şeklinde gösterirken aşikar kanama nadirdir. Crohn hastalığının üst GíS tutulumuna bağlı olarak komplikasyonlar da gelişebilir. Striktürler ve bunlara bağlı oluşan gasrik çıkış yolu obstrüksiyonu en sık izlenen komplikasyonlardandır. Diğer bir komplikasyon da fistül formasyonu olup duodenumla kolon, biliyer sistem, ince barsak ve pankreas arasında oluşabilir (11).

Gastroduodenal tutulumlu Crohn hastalı̆̆ının tedavisi medi- kal veya cerrahidir. Kanıta dayalı bir tedavi kılavuzu olmadığı için gastroduodenal tutulumlu Crohn hastalığında medikal tedavi klinik gözlem ve teorik bilgiye dayanır. Proton pompa inhibitörleri ve sterodiler çoğu zaman ilk tedavi seçeneğidirler. Steroidlerle yapılan çalışmalarda başarılı sonuçlar elde edilmiştir (12). Bu hastalarda çoğu zaman eşlik eden ileokolonik hastalık ve bunun için verilen medikal tedaviler aslında gastroduodenal $\mathrm{CH}$ tedavisinin temelini de oluşturmaktadır. Azatiopürin de bu grup hastalarda kullanılabilen ve inflamasyonu baskılayarak etkisini gösteren bir ilaçtır. Tümör nekrozis faktör anti-(TNF) grubu ilaçların bu hastalarda başarılı olduğu literatürde bildirilmiştir $(13,14)$. Bizim serimizde 3 hasta anti-TNF tedavisi alıyordu. Bu hastalarm hepsi bu tedaviyi primer olarak alt GIS tutulumundan dolayı almaktaydı. Medikal tedaviye direnç durumunda veya komplikasyonların gelişmesi halinde cerrahi tedavi ön plana geçer. Gastroduodenal CH'da bypass cerrahiler daha sık ve başarılı olurken rezeksiyonlar alt GIS tutulumlu CH'na göre daha az tercih edilir (15). Hastalarımızın hiçbirinin takip süreleri boyunca cerrahi ihtiyacı olmamıştı.

Serimizdeki hastaların takip sürelerinin heterojen olması bu çalışmanın en önemli eksikliğidir. Bazı hastaların takip süreleri 1 ile 6 ay arasında değişmekteydi. Buna bağlı olarak gastroduodenal tutulumlu hastaların medikal tedaviye yanitları, gelişen komplikasyonlar ve uygulanılan cerrahi prosedürler hakkında yeterli bir datamız yoktu.

Sonuç olarak gastroduodenal CH'nı tanımak her zaman kolay olmamaktadır. Crohn hastalığı tanısı olan bir bireyde gelişen epigastrik ağrı, bulantı-kusma ve disfaji gibi şikayetler üst GIS'in endoskopik incelenmesini zorunlu hale getirmektedir. Erken tanı ve uygun tedavi gelişebilecek komplikasyonların önüne geçebilir. Striktürler veya fistüllerin erken tanınması ve uygun tedavisi de bu hastalarda morbidite ve mortalitede azalmayla sonuçlanacaktır.

\section{KAYNAKLAR}

1. Crohn BB, Ginzburg L, Oppenheimer GD. Regional ileitis. A pathologic and clinical entity. JAMA 1932;99:1323-9.

2. Satsangi J, Silverberg MS, Vermeire S. The Montreal classification of inflammatory bowel disease: controversies, consensus and implications. Gut 2006;55:749-53.

3. Wagtmans MJ, van Hogezand RA, Griffioen G, et al. Crohn's disease of the upper gastrointestinal tract. Neth J Med 1997;50:S2-7.

4. Ingle SB, Adgaonkar BD, Jamadar NP, et al. Crohn' disease with gastroduodenal involvement: Diagnostic approach. World J Clin Cases 2015,3:479-83

5. Van Assche G, Dignass A, Panes J, et al. The second European evidence-based consensus on the diagnosis and management of Crohn's disease: definition and diagnosis. J Crohn's Colitis 2010;4:7-27.

6. Hisabe T, Hirai F, Matsui T, et al. Evaluation of diagnostic criteria for Crohn's disease in Japan. J Gastroenterol 2014;49:93-9.

7. Fujiya M, Sakatani A, Dokoshi T. A Bamboo joint-like appearance is a characteristic finding in the upper gastrointestinal tract of Crohn's disease patients: A case-control study. Medicine (Baltimore) 2015;94:e1500.

8. Diaz L, Hernandez-Oquet RE, Deshpande AR, et al. Upper gastrointestinal involvement in Crohn's disease: histopathologic and endoscopic findings. South Med J 2015;108:695-700.

9. Loftus EV Jr. Upper gastrointestinal tract Crohn's disease. Clin Perspect Gastroenterol 2002;5:188-91.

10. Van Hogezand RA, Witte AM, Veenendaal RA, et al. Proximal Crohn's disease. Review of the clinicopathologic features and therapy. Inflamm Bowel Dis 2001;7:328-37.

11. Rutgeerts P, Onette E, Vantrappen G, et al. Crohn's disease of the stomach and duodenum: a clinical study with emphasis on the value of endoscopy and endoscopic biopsies. Endoscopy 1980;12:288-94.

12. Yamamoto T, Allan RN, Keighley MR. An audit of gastroduodenal Crohn disease; clinicopathologic features and management. Scand J Gastroenterol 1999;34:1019-24.

13. Firth M, Prather C. Unusual gastric Crohn's disease treated with infliximab-A case report. Am J Gastroenterol 2002;97:S190.

14. Kim YL, Park YS, Park EK. Refractory duodenal Crohn's disease successfully treated with infliximab. Intest Res 2014;12:66-9.

15. Shapiro M, Greenstein AJ, Byrn J. Surgical management and outcomes of patients with duodenal Crohn's disease. J Am Coll Surg 2008;207:36-42. 